\title{
Increasing Freshman Contact with Engineers - A Revamp of ENGR101, Tulane's Freshman Intro to Engineering Course
}

\author{
Carol Mullenax, Cedric Walker \\ Tulane University
}

\begin{abstract}
In prior years, an entering freshman wanting to pursue a career in engineering could not either refute or verify that decision based on anything other than entry-level math and science classes until well after his first year of study. At Tulane, a third of the freshmen initially enrolling in the School of Engineering decided to pursue other majors by the end of their freshman year.

For the 2003-04 academic year, a new approach was taken for ENGR101, Tulane's Introduction to Engineering freshman course. The traditional one-hour weekly lecture format was changed, adding three departmental seminars with simultaneous sessions on topics of each department's choosing, guest speakers on topics of interest, and active learning modules as possible. Three additional elements were added as outside-the-classroom activities: mini-lab sessions conducted primarily by graduate students, lunch appointments with faculty members, and off-site visits with local engineering alumni.
\end{abstract}

Although Tulane's entering freshman engineering class is not large by some university standards, managing multiple activities for 220 students was not an easy task. A course website was created by the Tulane Innovative Learning Center specifically for use in this course, managing student sign-ups and scheduling for all outside-the-classroom activities.

Course funding was obtained through the Tulane Interdisciplinary Experiences (TIDES) program, designed specifically for entering freshmen but primarily organized through the liberal arts and sciences until this year. This funding vehicle allowed an increase in staffing for the course and underwrote the outside-the-classroom activities. An interesting side effect of joining in the TIDES program was that twelve non-engineering majors registered for the class; we are watching to see if they stay in engineering.

Changing so many class elements at once proved a logistical challenge, but it was accomplished with minor downscaling from initial plans. Student satisfaction with the course was increased, and retention numbers will be compared as they come available.

\section{Introduction}

Tulane University, a private university located in New Orleans, typically enrolls approximately two hundred freshmen stating an intention to study one of the fields of engineering. The vast

Proceedings of the 2004 American Society for Engineering Education Annual Conference \& Exposition Copyright $(\mathrm{C}$ 2004, American Society for Engineering Education 
majority of these students' freshman schedule is dominated by the basic foundation courses (calculus, physics, chemistry) which are administered through two colleges in Liberal Arts and Sciences. The only engineering-specific course is ENGR101, a one credit hour freshman introduction to engineering class.

In recent years, attrition from freshman year to sophomore year has neared one-third of the entering group; the majority of these students did not totally leave the university, rather they transferred to other majors at Tulane. In an effort to keep students in the engineering program, or at least to allow them to make an informed decision about their academic future, ENGR101 was redesigned for the 2003-2004 academic year and cross-listed as TIDE101; funding for the new program was obtained from the Tulane Interdisciplinary Studies (TIDES) Program, administered through the Provost's Office.

\section{Goals for revamping the course}

Based on input from upperclass undergraduates and the experiences of the course instructors, three areas were targeted for addition to the course: provide information needed to determine an engineering major, increase social interaction within the entire freshman engineering population, and increase contact with engineers (faculty, more advanced students, and alumni).

It was clear that all these efforts could not take place solely during the one-hour weekly lecture time assigned to the class, so the last listed goal was handled through outside-the-classroom activities. A field trip was also added to the list of outside-the-classroom activities.

The lectures themselves were restructured around specific objectives: learning skills, departmental overviews, rules/regulations, learning resources, career planning/opportunities, small group activities, and preparation for the field trip.

\section{Lecture modifications}

Tulane is on the semester system, and there were fourteen class lectures during the Fall semester.

Each lecture was kicked off with an engineering joke to lighten the tone. There are several from which to choose, and enough to populate the entire semester. A short period of announcements followed (including upcoming student club activities, if informed), then the main lecture topic(s).

\section{Lecture topics}

Prior art allocated one lecture day to each department/program for an overview of degree requirements, and several days spent on Rules/Regulations of the School. 
In an effort to change this rather dry formula, multiple topics were typically presented in the same day. Additionally, students were allowed to pick from simultaneous departmental seminar offerings to allow them to attend subjects of interest.

\section{Introduction / Learning Styles}

The first day of class involved an overview of course expectations, then an introduction to learning styles. The first assignment required students to take Felder's online Learning Styles Inventory, and comment upon their individual results.

\section{The Rules / Student Organizations}

One lecture was split between the Associate Dean giving the students an overview of the processes and procedures of the School of Engineering, then an advanced undergraduate student providing an overview of all engineering student organizations.

\section{Departmental introductions}

Two lecture days were allocated to brief introductions to each engineering department. Each day, three departments had the person of their choice (ranging from the department head to other faculty members) present a brief synopsis of the opportunities within their program.

\section{Small group activity}

We generated small groups (10 students) based on student learning style as determined by the Felder online LSI. Strong preferences in any learning style were grouped together, with visual learners subordinated to any other strong preference due to their large predominance. Students without strong preferences were grouped as most convenient.

Students were tasked with reverse-engineering the manufacture of Dippin' Dots, a type of ice cream available at specific concession stands. During the exercise, we circulated among the groups and observed the style of work and informed students of their like-minded group members. Sure enough, groups tended to perform to learning style. Dippin' Dots were available to eat during the exercise, and the class took place outdoors to facilitate the food and discussions.

Each group was required to turn in a drawing of their concept for the manufacture of Dippin' Dots, and individually each student was responsible for downloading the actual machine patent from the Blackboard site (counted as an assignment).

\section{Roller Coaster Construction / Dynamics}

The theme park in New Orleans was bought by the Six Flags chain and an expansion project undertaken which contracted a construction company owned by a Tulane engineering alumnus. While at the theme park, Cedric happened to speak with the CEO of Six Flags about a student field trip to the park and received favorable feedback on the idea.

To tie in engineering principles, the Tulane alum presented information on the initial construction of the theme park and the expansion, and the unique problems of building a roller 
coaster in a swamp. In the second segment of the lecture, a faculty member presented research on rider forces on a roller coaster. This lecture preceded the group field trip to Six Flags amusement park by three days.

\section{Departmental seminars}

Three lecture days were devoted to presentations by each of the engineering departments, offered simultaneously in different locations. Students were allowed to attend no more than two seminars by a given department. Attendance was recorded, and the department noted in the student's gradebook.

\section{More Rules / Learning Resources}

Timed to coincide with delivery of freshman midterm grades, the Associate Dean spoke on how to interpret grades, and withdraw from classes if necessary. A staff member of the Educational Resource Center then informed students of tutoring opportunities.

\section{More Rules / Career Development \& Planning}

The Associate Dean gave registration advice for the Spring semester. A staff member from the Career Center presented the ins and outs of internships and summer jobs, and quoted career earnings possibilities. All students were assigned to generate and deliver a personal résumé.

\section{Engineering Research}

We provided an overview of research, then specific examples of research in industry and academia (undergraduate and graduate).

$\underline{\text { 3D Visualization in Design }}$

A faculty member provided examples of visualization tools/techniques in engineering.

\section{$\underline{\text { Assessment }}$}

Student course assessments are not made public from the School of Liberal Arts \& Sciences (LAS), which administers much of the required freshman curriculum for Engineering (physics, chemistry, calculus, etc.), so the Engineering Dean's Office administered its own student survey for LAS classes. Social time outside followed, with holiday food and drink provided.

\section{Outside activities}

In addition to the above fourteen lectures, students were required to participate in activities outside their normal lecture hour. These activities included a lunch with an engineering faculty member, mini-labs taught by students in the engineering research labs, a site visit to the place of employment of a Tulane engineering alumna/us, and an optional field trip to Six Flags amusement park. 
Administering the lunches and labs was accomplished through a custom-designed website designed by the Innovative Learning Center at Tulane. ${ }^{[1]}$ Due to time constraints, alumni trips were postponed until the Spring semester class, TIDE102.

\section{Faculty lunches}

Faculty members in each department were asked to take freshmen, singly or in pairs, to lunch. Funding was provided through the TIDES budget, and faculty had the opportunity to read through enrolled students' files before the approximate one-hour meeting. Students signed up for dates and times which the faculty members had specified as available for this activity. A range of days and times for the lunches was obtained from faculty in a variety of departments to guard against a student's schedule precluding participation in this segment of the course.

A total of 25 faculty hosted lunches for the 201 freshmen who attended them. Student compliance for this required activity was $92 \%$.

\section{$\underline{\text { Benefits }}$}

Students were able to select faculty who were interesting in some way to them, and select scheduled times compatible with their courses. They were able to talk to faculty in a nonthreatening environment and ask nontechnical questions (course/major advice, etc.).

\section{Difficulties}

The individual scheduling, although more convenient for both faculty \& student, resulted in many no-shows by freshmen. They are, after all, freshmen, and for many of them this was the first time for them to single-handedly be responsible for their own schedule.

Lunches scheduled early in the semester often went unenrolled. Lunches at the end of the semester were typically packed.

\section{Mini-labs}

Graduate students were solicited to create/conduct small-scale simplified experiments in the research laboratories. Payroll and consumable supply expenses were funded through the TIDES budget. Target enrollment for any given lab session was two or three freshmen. Composition, duration, and requirements (reports, etc.) for each lab topic were left to the discretion of the lab instructor (with suggestion and input from us).

In the first iteration, graduate students submitted ideas for mini-labs which were approved first by the TIDES instructors and then by the faculty members controlling whatever equipment $\&$ lab space was needed. Documentation for each lab included a mini-syllabus and pre-lab document posted to the website so that students could decide which labs to select. 
Enough labs to support the entire class enrollment were not obtained through this first method, so a plea was made to the department heads to increase the number of available labs. The departments used various means to encourage generation of labs, ranging from calling this work part of existing Teaching Assistant (TA) appointments to performing more subtle arm-twisting. In total, 25 student instructors conducted lab sessions in 27 distinct topic areas. A more detailed account of the mini-labs is reported elsewhere. ${ }^{[2]}$

\section{$\underline{\text { Benefits }}$}

Freshmen were allowed into the research labs, had the opportunity to interact with a graduate student or advanced undergraduate during the lab session, got to see both the people who do research as well as what kind of work can be done, (in some labs) had the opportunity to write a limited lab report, and could rate and comment on the lab.

Lab instructors had the opportunity to develop a small learning module, and then modify it based on multiple offerings; if they required a lab report, they got feedback through the reports to see if important points were being understood by the students. Scheduling of lab sessions was at their convenience, and most enrolled students were interested in the subject matter.

\section{Difficulties}

As with the faculty lunches, no-shows were a problem. Out of 178 offered lab sessions and 357 attendees, there were 99 no-shows. This is an unacceptable number, and measures must be taken in the future to decrease no-shows.

A major challenge for this segment of the course was the initial generation of lab topics. While we now have a "set" of lab topics to work from for next year as well as a group of instructors who wish to participate in the program again, the future turnover of instructors as people complete their degrees will require a search for instructors each year.

Early lab sessions often had empty enrollments, and sessions later in the semester were sometimes overbooked as freshmen would show up and see if they could participate in a lab even if they were not enrolled for it.

\section{Field trip to Six Flags}

An agreement was reached with a local theme park to allow access to the facility an hour before opening for a "behind-the-scenes" tour of a construction expansion from Spring, 2003. The construction company responsible for much of the foundation work in this addition was headed by a Tulane alum, and he provided three engineers from his firm who led small subgroups on tours of the grounds and answered questions (not necessarily just about the park).

\section{$\underline{\text { Logistics }}$}

The TIDES office instigated a required deposit to discourage no-shows, so $\$ 20$ was collected at sign-up for each attending student. $\$ 10$ was returned to each student when he/she showed up to 
board buses to the park on a Saturday morning. Approximately 60 students arrived at 9 a.m. and had one hour of tours (foundations, safety, control systems) before getting the first ride on the marquee roller coaster at the park's opening. At that point, all students were released for a day of fun at the park; two bus return times were offered.

\section{Results of the new program}

The ultimate result of the revamped course will be the retention of students in Engineering. Only three students withdrew from the course during the semester. Preliminarily, 145 students have registered for the Spring engineering freshman course with more expected as the semester approaches. Even at this early stage, this is no worse than what we have seen for retention in the past few years (Fig. 1).

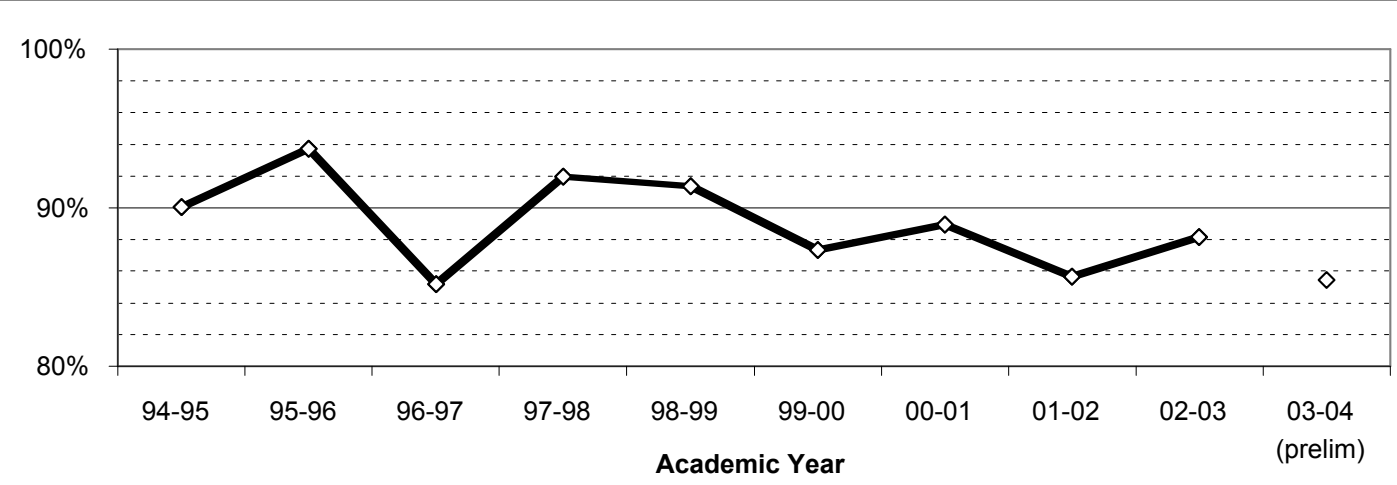

Figure 1: Freshman engineering retention through the Freshman year

208 students filled out an online anonymous survey about the course. In this, $80 \%$ felt that the course either strengthened their choice of engineering as their course of study or added value to that decision. Moreover, few students felt that specific activities of the course were not valuable uses of their time: $6 \%$ for faculty lunches, $15 \%$ for mini-labs, $13 \%$ for departmental seminars. Only $4 \%$ of the respondents indicated their intention not to enroll in ENGR102, the Spring freshman engineering course.

The only real negatives that we have heard regarding this program have been from upper-level undergraduates who lament that things were not like this when they took the course.

\section{Future plans}

One of the questions in the survey asked students what they would like to have added to the course, and the most frequent answer was another small group activity. Additionally, we would like to have enough lab sessions to offer three to each student. The website will be updated to hold more of the task completion reporting data and ease grade reporting duties. 


\section{Conclusions}

Overall we feel that the changes in our freshman engineering program have been successful. We have promoted greater interaction among the various engineering populations at the School, have added useful content to the course, and have presented things in a manner that was agreeable to the freshmen.

The one major indicator of success, retention to the sophomore year, will not be available until at least May, 2004. The preliminary indication from the survey is that no more than $10 \%$ of the students intend to leave engineering (assuming that all non-respondents leave). If this is true, it will be a significant increase in retention from recent years.

Only time will tell.

\section{REFERENCES}

1. Orth Wright L, Robinson DE, Mullenax CA. A Comprehensive Activities Management Website for Tulane's Freshman Intro to Engineering Course. 2004 ASEE Annual Conference Proceedings. 2004.

2. Mullenax CA, Walker CF. Adding Mini-Labs to ENGR101, Tulane's Freshman Intro to Engineering Course. 2004 ASEE Annual Conference Proceedings. 2004.

CAROL MULLENAX, P.E.

Carol Mullenax is a Doctoral Candidate in Biomedical Engineering at Tulane University in New Orleans while on leave of absence from The Boeing Company. She received her BS in Engineering \& Applied Science from Caltech in 1989, and an MS in Mechanical Engineering from Washington University (St. Louis) in 1995. Carol served as course administrator for ENGR101 and conducted multiple sessions in each of four mini-lab topics for the course.

CEDRIC WALKER, P.E.

Cedric Walker is Professor of Biomedical Engineering at Tulane and was a founding member of that department in 1977. He earned his BS and MS at Stanford University and the Ph.D. at Duke University. Cedric was course coordinator for ENGR101. 